\title{
Aerosols and health: a challenge for chemical and biological analysis
}

\author{
Ralf Zimmermann ${ }^{1,2}$
}

Published online: 14 July 2015

(C) Springer-Verlag Berlin Heidelberg 2015

In the industrialized countries, air pollution represents the most severe environmental impact on human health. Since the early studies on the health effects of the London smog episode in 1952 [2, 24], an enormous amount of epidemiological, toxicological, medical, chemical, physical, and technological research was conducted in order to understand and prevent the effects of air pollution, especially with fine particulate matter, on human health [1, 7, 9, 12, 13, 17, 19, 20, 25]. The legislation and abatement measures based on this work have considerably improved the air quality in many industrialized countries. However, despite all the undertaken measures, air pollution still is the most potent environmental (pollution) health threat in the first world [20]. Based on this paradigm, a scientific session at the Analytica Conference 2014 in Munich and a workshop at Helmholtz Zentrum on the topic Aerosols and Health: A challenge for chemical and biological analysis were organized and conducted. Thereafter, this topical issue was planned and compiled, similarly to a previous topical issue "Aerosol Analysis" on Organic

Published in the topical collection Aerosols and Health with guest editor Ralf Zimmermann.

Ralf Zimmermann

ralf.zimmermann@helmholtz-muenchen.de;

ralf.zimmermann@uni-rostock.de

1 Joint Mass Spectrometry Centre at the University of Rostock and Helmholtz Zentrum München, Chair of Analytical Chemistry, Institute of Chemistry, University of Rostock, Dr.-Lorenz-Weg 1, 18051 Rostock, Germany

2 Joint Mass Spectrometry Centre at the University of Rostock and Helmholtz Zentrum München, Comprehensive Molecular Analytics, Helmholtz Zentrum München - German Research Centre for Environmental Health $\mathrm{GmbH}$, Ingolstädter Landstraße 1, 85764 Oberschleißheim, Germany compounds in fine and ultrafine dust-Analysis and impact on human health, which was previously published in Analytical and Bioanalytical Chemistry [26]. The present topical issue consists of a feature article, a critical review, and seven research papers, with four contributions coming from the consortium Helmholtz Virtual Institute of Complex Molecular Systems in Environmental Health - Aerosols and Health (HICE, www.hice-vi.eu), which tries to combine a comprehensive analysis of aerosol properties and composition with a multi-omics comprehensive analysis of the biological effects of the aerosol onto human lung cells to improve the knowledge on the effect mechanisms [14]. Below, the contributions of this topical issue on Aerosol and Health: A challenge for chemical and biological analysis are briefly introduced.

The feature article of Gilmour, Kim, and Hays from the US Environmental Protection Agency addresses the importance of the organic composition of particulate matter (PM) from diesel engines and wildfires (i.e., bio mass burning) for health effects, in particular for (allergic) lung inflammation. They conclude that a deeper knowledge on the organic PM composition as well as the implementation of new, more efficient approaches for toxicity testing, including cell-based methods, is required. It is suggested to address several challenges in the future for improving the knowledge of the health impacts of combustion emissions. This includes the generation of combustion emission standards (see in this context also the contribution of Müller et al. on the characterization of a CAST combustion reference aerosol generator in this issue), developing validated approaches for toxicity prediction, identifying common health outcomes, and extrapolation of chronic exposure effects, including adaptive and recovery responses. Furthermore, the authors propose to better study the influence of susceptibility factors (e.g., illnesses or genetic variability) and the effects of complex mixtures (synergistic and antagonistic 
effects). A critical review included in this topical issue by Parshintsev and Hyötyläinen from Helsinki University and Steno Inc. summarizes the state-of-the-art in analytical methodology for characterization of organic compounds in atmospheric aerosol particles. They distinguish off-line and on-line methods and discuss advantages and disadvantages of the individual techniques, concluding that further method development and combination of different on-line and off-line techniques is needed for a more thorough comprehension of the composition and dynamics of organic compounds in the atmosphere. The following five research papers report on new applications and approaches for characterizing organic compounds in aerosols. The on-line real-time analysis of the particle composition by mass spectrometry is, in particular, an important aspect for understanding atmospheric transformation processes. Although the technology of Aerosol Mass Spectrometry (AMS, Aerodyne Inc., USA) [10] had a strong impact on atmospheric chemistry research in the last years, a renaissance of the classic laser-based single particle aerosol time of flight mass spectrometry (ATOFMS) [18] could be foreseen. This trend is fueled also by the recently established possibility to obtain quantitative ATOFMS data [8], similarly as by the AMS approach. The ATOFMS approach has also the capability to detect sum values for elemental and organic carbon $(E C / O C)[6]$ and specific organic compounds. The contribution of Healy et al. from University of Toronto reports in this context on single-particle resolved speciation of alkylamines in ambient aerosol at five European cities. The authors could detect large fractions of alkylamine-containing aerosol particles in all five cities, with trimethylamine being the most prominent species. In some places, however, other alkylamine species also occur because of -in one case external and in another case internal- mixing. The article of Müller et al. from Helmholtz Zentrum München (HICE contribution) focuses on the investigation of the chemical composition (PAH) and physical properties (i.e., light absorption at different wavelengths for detection of organic-rich "brown carbon" and rather soot-like "black carbon") of a standard reference aerosol generated by a flame soot generator (CAST, Jing-Cast Ltd., Switzerland). In addition to off-line chemical analyses (GC-MS for PAH), on-line mass spectrometry (AMS) and further on-line aerosol monitoring techniques are also applied. As discussed before, a reliable and reproducible on-line combustion aerosol standard is important for e.g., toxicological tests, and the CAST system is a reasonable candidate for such a standard system with tunable properties: depending on the air-fuel mixing ratio the physical properties and the composition of organic compounds (mainly PAH) can be adjusted. Addressing the vast complexity of combustion aerosol particles is a particular challenge. Still a large fraction of the organic inventory of emission- and ambient-PM is unidentified [3]. As described in the review within this topical collection, several high-end analytical chemical approaches based on mass spectrometry, such as comprehensive two-dimensional gas chromatography-time-of-flight mass spectrometry [23] or ultra-high resolution mass spectrometry [21] can be used to address the yet unknown chemical space of aerosol PM. An important aspect for all mass spectrometric technologies, however, in this context is the ionization method used for the mass spectrometric detection. Different ionization methods such as electrospray ionization (ESI), atmospheric pressure photo ionization (APPI), electron ionization (EI), or matrix assisted laser desorption ionization (MALDI) can address different molecules, depending on the molecular weight, structure, elemental composition, and physical chemical properties and the type of sample and, furthermore, all have specific strengths and weaknesses. Thus the development, evaluation, and comparison of different ionization methods for PM analysis is very important for the research field. The publication of Rüger et al. from University of Rostock (HICE contribution) discusses the characterization of primary emission particulate matter from a ship diesel engine at the molecular level by means of laser desorption ionization (LDI)-ultra-high resolution mass spectrometry. The developed method could be directly applied to PM deposits collected by an impactorbased PM-sampling device. The high mass resolution and accuracy of the used FT-ICR mass analyzer allows a quick profiling using only a minimal sample size. By using an imaging approach for characterization of the structures formed by the deposited PM, LDI-artifacts such as fullerene formation from soot at higher laser fluences could be studied and avoided. In the publication, lastly the composition of ship engine emission particles are compared with the composition of the fuel (heavy fuel oil), showing that a large fraction of the compounds in the aerosol particles is actually stemming from unburnt fuel. An aerosol is defined as solid or liquid microand nanoparticles dispersed in a gaseous phase. If the health effects of aerosols are addressed, an important but often neglected aspect is the impact of the gas-phase composition. Combustion effluents and ambient aerosols (e.g., during photochemical smog conditions) often contain quite large amounts of reactive or toxic gases, such as butadiene, aldehydes, ozone, or benzene. Often the mass concentrations of toxic gas-phase constituents are higher than the PM concentration. The synergy of PM and toxic gases in the emission and ambient aerosols might thus be particularly relevant for health effects as the small, inhalable particles supposedly act as carrier for adsorbed toxic gas-phase species, potentially transporting them through the denuding sections of the airway system in the vulnerable deeper regions of the lung. This scenario motivates the study of relevant gaseous compounds in emissions and the ambient environment. The highly dynamic changes of gas-phase concentrations in many emission sources suggest the use of real-time on-line analysis methods. Recently, several on-line mass spectrometric analysis systems based on soft ionization by either chemical ionization (CI) or 
photo ionization (PI) became available (e.g., IONICON, Austria; Photonion, Germany). The contribution of Radischat et al., University of Rostock (HICE contribution) focuses on the real-time mass spectrometric analysis of organic compounds in ship engine aerosol emissions using the PI and CI methods of resonance-enhanced multiphoton ionization-mass spectrometry and proton transfer-mass spectrometry. The ship engine was operated either with diesel fuel (DF) or heavy fuel oil (HFO) at different engine parameters (e.g., load or fuel injection parameters). The on-line real-time approach allows the coverage of dynamic processes (e.g., change of the type of fuel). It was observed that the emission of most gas-phase compounds is considerably higher in case of HFO use. This was also observed for the organic compounds in the particulate matter [14]. The performed on-line gas-phase exhaust measurements furthermore depict that low loads and the operation of the engine in idling mode cause particularly high emissions of carboxylic and aromatic compounds.

In order to understand the aerosol-induced biological effects and, in the long run, also the human health effects, in addition to the chemical information on known toxicants or potentially toxic compounds in the aerosol, as well as the toxicological or biological response information from aerosol-exposed biological systems need to be analyzed. Only as a first approximation, a rough evaluation of the toxicity potential of PM or gases can be performed by chemical target analysis of relevant known toxicants in the PM, using known toxicity- or toxicity-equivalence values of well-known compounds such as PAH [15]. Another possibility is the use of chemical assays using indicator reactions (e.g., for the oxidative potential of emission particles [5], which is believed to be connected with induction of inflammatory processes in lung and other target organs [22]. The application of lung cellbased assays in this context promises to be a reproducible tool for accessing initial biological responses of the primary target tissue on collected PM [9] or, if adequate exposure technologies are used, directly on emission- or ambient aerosols [16]. However, the study of systemic effects finally needs animal[4] or human patient studies. The latter approaches, however, are largely limited by cost and ethical restrictions. Cell-based test systems thus are considered as a good option for standard testing of the initial biological effects induced by aerosol- or PM-exposure. This topical issue reports on three cell-based studies on the PM or aerosol toxicity.

An important strategy to address the components in the aerosol, which are responsible for biological effects in cellular systems, lies in the fractionation of the sample in chemically different, less complex sub-fractions, and subject those individually to the cell test assays. This principle was applied in the work "Assessing the Role of Chemical Components in Cellular Responses to Atmospheric Particle Matter (PM) Through Chemical Fractionation of PM Extracts" by Heo et al. from University of Wisconsin-Madison. The authors investigated the role of different water-soluble metals on lung cells. Water extracts from ultrafine particles $\left(\mathrm{PM}_{0.25}\right)$ collected on filters at different places in the Los Angeles region were generated. By using different metal-chelating agents, the authors generated different soluble metal-containing chemical fractions. A rat alveolar macrophage model (NR8383) was used in submerse cell culture to determine the formation of reactive oxygen species (ROS) and the pro-inflammatory tumor necrosis factor $\alpha(\mathrm{TNF} \alpha)$ by a fluorescence- and an ELISA-assay with the different generated fractions, respectively. The authors summarize that the transition metals Mn, $\mathrm{V}$, and $\mathrm{Fe}$ are the most important soluble metals generating oxidative stress (ROS-formation) in conclusion with (e.g., epidemiological studies). The contribution of Kanashova et al. from the Max Delbrück Centre of Molecular Medicine (HICE contribution) describes a different approach of chemical fractionation in their work. Collected emission particles from a ship diesel engine operated with heavy fuel oil (HFO) were investigated. The HFO-particles contain a large fraction of semi-volatile and low-volatile compounds that were thermally stripped in a thermal analysis instrument at 280 and $580{ }^{\circ} \mathrm{C}$, respectively. Murine macrophages (RAW 647.5) were exposed to the untreated and thermally treated fractions. The biological response of the cells was investigated by a differential proteomic analysis of the exposed mouse macrophages using an automated sample preparation workflow. An interesting aspect is the much more comprehensive bioanalytical approach for effects monitoring. Instead of investigating only a limited number of endpoints, the concentration of thousands of proteins were determined in a quantitative proteomics approach using stable isotope labeling (SILAC) for referencing. By this approach, the course of several biological pathways can be assessed, for example, results of the successive removal of the adsorbates in a decreasing activity of DNA-damage and repair. This might be explained by the removal (i.e., vaporization) of the polycyclic hydrocarbons. Many other important pathways, including the enhancement of the phagocytosis (i.e., the engulfment of particles) by ship emission particles were described. The last contribution in the topical collection by Steiner et al. from the University of Fribourg studies the effects of an iron-based fuel-borne catalyst and a diesel particle filter on exhaust toxicity in lung cells in vitro. An important parameter in lung cell-based test systems is the type of PM or aerosol exposition. Routinely, lung cell cultures are exposed to collected PM samples in submersed culture (see the two previous contributions). A suspension of the PM sample in a solvent is added to the medium in which the cells are growing. This approach has advantages (e.g., in simplicity and technical reproducibility) but obviously does not reflect the natural exposure situation well. Recently developed air liquid interface (ALI) technologies, in which the cells are growing in general as a confluent layer on a semipermeable membrane in contact with the liquid culturing media, allow a much more 
realistic exposure approach by mimicking the situation in the lung $[11,16]$. An important aspect in the study is that the more realistic exposure scenario at the air liquid interface (ALI) is applied for the exposure of the lung cell culture composed of lung cell line (16HBE140 $\mathrm{o}^{-}$) and primary (human blood monocyte derived macrophages) cells. The cells are ALI-exposed for different times to exhaust of a diesel engine with and without diesel particulate filter. Diesel fuels with different additives are used. The cells are exposed for different times to the diluted emission aerosol and the cytotoxicity (LDH-release), oxidative potential, as well as interleukin 8- and $\mathrm{TNF} \alpha$-gene expression and secretion is measured. The outcome is that the particulate filter, depending on the additives, does not reduce all toxic effects of the exhaust gas, as reactive gases (or very small nanoparticles) are still emitted. Steiner et al. conclude that a more comprehensive aerosol characterization is required to better understand the observed biological effects in future.

Summarizing the scientific session at Analytica 2014, the workshop and the publications presented in this topical issue of Analytical and Bioanalytical Chemistry on Aerosols and Health: A challenge for chemical and biological analysis the state-of-the-art and research gaps have been identified and discussed. The previous workshop and special issue from 2011 [26] resulted in the proposal and finally establishment of the HICE-consortium with some of the first results now being presented and discussed within this topical issue and in other publications [14]. However, it becomes clear that a better understanding of aerosol-related health effects will remain a huge task for the decades to come.

Last but not least, I hope that the readers of Analytical and Bioanalytical Chemistry are interested in the contributions on the interdisciplinary field of Analytical Sciences in Aerosol and Health research compiled in this special issue.

\section{References}

1. Allen JO, Dookeran NM, Taghizadeh K, Lafleur AL, Smith KA, Sarofim AF (1997) Measurement of oxygenated polycyclic aromatic hydrocarbons associated with a size-segregated urban aerosol. Environ Sci Technol 31:2064-2070

2. Bell ML, Davis DL (2001) Reassessment of the lethal London fog of 1952: novel indicators of acute and chronic consequences of acute exposure to air pollution. Environ Health Perspect 109:389-394

3. Bi X, Simoneit BRT, Sheng G, Ma S, Fu J (2008) Composition and major sources of organic compounds in urban aerosols. Atmos Res $88: 256-265$

4. Boylen CE, Sly PD, Zosky GR, Larcombe AN (2011) Physiological and inflammatory responses in an anthropomorphically relevant model of acute diesel exhaust particle exposure are sex and dose-dependent. Inhal Toxicol 23:906-917

5. Crilley LR, Knibbs LD, Miljevic B, Cong X, Fairfull-Smith KE, Bottle SE, Ristovski ZD, Ayoko GA, Morawska L (2012) Concentration and oxidative potential of on-road particle emissions and their relationship with traffic composition: relevance to exposure assessment. Atmos Environ 59:533-539

6. Ferge T, Karg E, Schröppel A, Coffee KR, Tobias HJ, Frank M, Gard EE, Zimmermann R (2006) Fast determination of the relative elemental and organic carbon content of aerosol samples by on-line single-particle aerosol time-of-flight mass spectrometry. Environ Sci Technol 40:3327-3335

7. Ghio AJ (2004) Biological effects of Utah Valley ambient air particles in humans: a review. J Aerosol Med [Deposition Clearance and Effects in the Lung] 17:157-164

8. Healy RM, Sciare J, Poulain L, Crippa M, Wiedensohler A, Prévôt AS, Baltensperger U, Sarda-Estève R, McGuire ML, Jeong CH, McGillicuddy E, O'Connor IP, Sodeau JR, Evans GJ, Wenger JC (2013) Quantitative determination of carbonaceous particle mixing state in Paris using single-particle mass spectrometer and aerosol mass spectrometer measurements. Atmos Chem Phys 13:94799496

9. Jalava PI, Happo MS, Kelz J, Brunner T, Hakulinen P, MakiPaakkanen J, Hukkanen A, Jokiniemi J, Obernberger I, Hirvonen M-R (2012) In vitro toxicological characterization of particulate emissions from residential biomass heating systems based on old and new technologies. Atmos Environ 50:24-35

10. Jayne JT, Leard DC, Zhang XF, Davidovits P, Smith KA, Kolb CE, Worsnop DR (2000) Development of an aerosol mass spectrometer for size and composition analysis of submicron particles. Aerosol Sci Technol 33:49-70

11. Knebel JW, Ritter D, Aufderheide M (1998) Development of an in vitro system for studying effects of native and photochemically transformed gaseous compounds using an air/liquid culture technique. Toxicol Lett 96(97):1-11

12. Koike, E, Yanagisawa, R, Takano, H. Toxicological effects of polycyclic aromatic hydrocarbons and their derivatives on respiratory cells. Atmos Environ

13. Oberdorster G (2000) Toxicology of ultrafine particles: in vivo studies. Philos Trans Royal Soc London, Ser A 358:2719-2739

14. Oeder S, Kanashova T, Sippula O, Sapcariu SC, Streibel T, Arteaga-Salas JM, Passig J, Dilger M, Paur H-R, Schlager C, Mülhopt S, Diabaté S, Weiss C, Stengel B, Rabe R, Harndorf H, Torvela T, Jokiniemi JK, Hirvonen M-R, Schmidt-Weber C, TraidlHoffmann C, BéruBé KA, Wlodarczyk AJ, Prytherch Z, Michalke B, Krebs T, Prévôt ASH, Kelbg M, Tiggesbäumker J, Karg E, Jakobi G, Scholtes S, Schnelle-Kreis J, Lintelmann J, Matuschek G, Sklorz M, Klingbeil S, Orasche J, Richthammer P, Müller L, Elsasser M, Reda A, Gröger T, Weggler B, Schwemer T, Czech H, Rüger CP, Abbaszade G, Radischat C, Hiller K, Buters JTM, Dittmar G, Zimmermann R (2015) Particulate matter from both heavy fuel oil and diesel fuel shipping emissions show strong biological effects on human lung cells at realistic and comparable in vitro exposure conditions. Plos One 10, e 0126536

15. Orasche J, Seidel T, Hartmann H, Schnelle-Kreis J, Chow JC, Ruppert H, Zimmermann R (2012) Comparison of emissions from wood combustion. Part 1: Emission factors and characteristics from different small-scale residential heating appliances considering particulate matter and polycyclic aromatic hydrocarbon (PAH)-related toxicological potential of particle-bound organic species. Energ Fuels 26:6695-6704

16. Paur H-R, Cassee FR, Teeguarden J, Fissan H, Diabate S, Aufderheide M, Kreyling WG, Hanninen O, Kasper G, Riediker M, Rothen-Rutishauser B, Schmid O (2011) In-vitro cell exposure studies for the assessment of nanoparticle toxicity in the lung-a dialog between aerosol science and biology. J Aerosol Sci 42:668692

17. Pope C (2008) Air pollution studies using the harvard six-cities and the ACS cohorts: What we have learned and what we still don't know. Epidemiology 19:S31-S32 
18. Prather KA, Nordmeyer T, Salt K (1994) Real-time characterization of individual aerosol particles using time-of-flight mass spectrometry. Anal Chem 66:1403-1407

19. Qadir RM, Abbaszade G, Schnelle-Kreis J, Chow JC, Zimmermann R (2013) Concentrations and source contributions of particulate organic matter before and after implementation of a low emission zone in Munich, Germany. Environ Pollut 175:158-167

20. Rueckerl R, Schneider A, Breitner S, Cyrys J, Peters A (2011) Health effects of particulate air pollution: a review of epidemiological evidence. Inhalation Toxicol 23:555-592

21. Schmitt-Kopplin P, Gelencsér A, Dabek-Zlotorzynska E, Kiss G, Hertkorn N, Harir M, Hong Y, Gebefügi I (2010) Analysis of the unresolved organic fraction in atmospheric aerosols with ultrahighresolution mass spectrometry and nuclear magnetic resonance spectroscopy: organosulfates as photochemical smog constituents. Anal Chem 82:8017-8026

22. Valavanidis A, Vlachogianni T, Fiotakis K, Loridas S (2013) Pulmonary oxidative stress, inflammation, and cancer: respirable particulate matter, fibrous dusts, and ozone as major causes of lung carcinogenesis through reactive oxygen species mechanisms. Int $\mathbf{J}$ Environ Res Public Health 10:3886-3907

23. Welthagen W, Schnelle-Kreis J, Zimmermann R (2003) Search criteria and rules for comprehensive two-dimensional gas chromatography-time-of-flight mass spectrometry analysis of airborne particulate matter. J Chromatogr A 1019:233-249

24. Whittaker A, BeruBe K, Jones T, Maynard R, Richards R (2004) Killer smog of London, 50 years on: particle properties and oxidative capacity. Sci Total Environ 334:435-445

25. World Health Organization (2013) Review of evidence on health aspects of air pollution. REVIHAAP Project Technical Report. WHO Regional Office Europe, Bonn
26 Zimmermann R (2011) Ambient aerosols and human health: working towards a combined analytical and toxicological approach. Anal Bioanal Chem 401:3041-3044

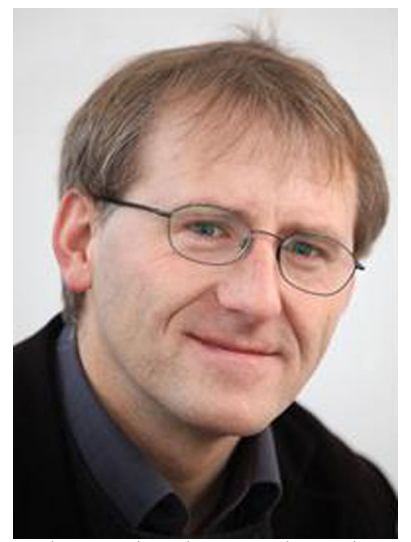

Ralf Zimmermann is Full Professor of Analytical Chemistry at the University of Rostock (UR) and also Head of the Cooperation Group "Comprehensive Molecular Analytics (CMA)" at the Helmholtz Zentrum München (HMGU). The Chair of Analytical Chemistry and the CMA together represent the Joint Mass Spectrometry Centre of UR and HMGU (JMSC, www.jmsc.de), which is also headed by Professor Zimmermann. Currently he is spokesperson of an international consortium, the Helmholtz Virtual Institute of Complex Molecular Systems in Environmental Health - Aerosols and Health (HICE, www.hice-vi.eu), which is investigating health effects of combustion aerosols by the integrated analysis on chemical and physical emission aerosol properties and molecular biological effects in aerosol exposed human lung cell models. His research interests include instrumental development and application of photoionization mass spectrometry, comprehensive multidimensional chromatography, industrial process analysis, applied combustion research, and aerosol analysis as well as metabolomics and analyses of biological effects in lung cell models. 